\title{
PSK, a Polysaccharide from Coriolus vesicolor, Enhances Oxygen Metabolism of Murine Peritoneal Macrophages and the Host Resistance to Listerial Infection
}

\author{
By HAJIME SAITO, HARUAKI TOMIOKA* AND KATSUMASA SATO \\ Department of Microbiology and Immunology, Shimane Medical University, Izumo 693, Japan
}

(Received 26 August 1987; revised 8 December 1987)

\begin{abstract}
PSK, a protein-bound polysaccharide isolated from the basidiomycete Coriolus vesicolor (Fr.) Quél. was examined with regard to its effects of macrophage $(\mathrm{M} \phi)$ oxygen metabolism in mice, a function important for the expression of $\mathrm{M} \phi$ antimicrobial activity. The $\mathrm{O}_{2}^{-}$-producing ability and chemiluminescence $(\mathrm{CL})$ of host peritoneal $\mathbf{M} \phi \mathbf{s}$ in response to phorbol myristate acetate were markedly elevated by preinjection of PSK ( 1 or $5 \mathrm{mg}$ per mouse intraperitoneally) around 4-7 d before $\mathrm{M} \phi$ harvest. The enhanced $\mathrm{O}_{2}^{-}$-producing ability due to PSK injection persisted much longer than the enhanced $\mathrm{CL}$, indicating a discrepancy in regulation of generation of active oxygen species such as $\mathrm{O}_{2}^{-}, \mathrm{H}_{2} \mathrm{O}_{2}, \mathrm{OH}$, and ${ }^{1} \mathrm{O}_{2}$. Daily injections of PSK $(1 \mathrm{mg}$ per injection) from 10 to $4 \mathrm{~d}$ before $\mathrm{M} \phi$ harvest did not increase the efficacy of PSK over that given by a single $1 \mathrm{mg}$ injection. When PSK $(5 \mathrm{mg})$ was given intraperitoneally to mice in a single injection 10,7 or $4 \mathrm{~d}$ before intravenous Listeria monocytogenes inoculation, a similar increase in the host resistance to the bacteria was noted regardless of the timing of the injection. Multiple PSK injections from 10 to $4 \mathrm{~d}$ before the infection also enhanced the host resistance, to the same degree. Therefore, PSK is thought to augment the host resistance to certain intracellular parasites including L. monocytogenes at least to some extent by enhancing oxygen metabolism of the host $\mathrm{M} \phi \mathrm{s}$.
\end{abstract}

\section{INTRODUCTION}

Immunopotentiators, such as BCG (Borsos \& Rapp, 1973), Corynebacterium parvum (Halpern et al., 1973), OK-432 (a streptococcal preparation) (Shiraishi et al., 1979), and Lactobacillus casei preparations (Kato et al., 1981 ; Saito et al., 1986 b; Sato, 1984) can protect against experimental microbial infections due to opportunistic pathogens. PSK, a protein-bound polysaccharide preparation isolated from the basidiomycete Coriolus versicolor (Fr.) Quél., consisting mainly of glucan and acidic peptide (Tsukagoshi et al., 1984), also enhances the host resistance to microbial infections such as those due to Listeria monocytogenes (Nomoto, 1981), Pseudomonas aeruginosa (Mayer \& Drews, 1980) and Candida species (Uetsuka et al., 1980), particularly in hosts with immunodeficiency due to malignant tumours or immunosuppressive treatment. PSK stimulates host macrophages $(\mathrm{M} \phi \mathrm{s})$ and polymorphonuclear leucocytes (PMNs) causing an increase in chemotactic response, phagocytosis, pinocytosis and cell spreading, and this may be important for the PSK-mediated enhancement of host resistance to microbial infections (Nguyen \& Stadtsbaeder, 1980). Thus, it was of interest to determine whether this agent enhances the oxidative metabolism of phagocytic cells, which is closely related to their microbicidal function (Johnston, 1978; Klebanoff \& Hamon, 1975; Nathan et al., 1979), and to study the protective effect of PSK on murine infections induced by $L$. monocytogenes.

\footnotetext{
Abbreviations: CL, chemiluminescence; i.p., intraperitoneal(ly); i.v., intravenous(ly); M $\phi$, macrophage; NBT, nitroblue tetrazolium; PEC, peritoneal exudate cell; PMA, phorbol myristate acetate; PMN, polymorphonuclear leucocyte.
} 


\section{METHODS}

Mice. Female ddY mice (5 weeks old) were purchased from Shizuoka Laboratory Animal Center, Shizuoka, Japan.

Organisms. Listeria monocytogenes EGD (from Dr K. Takeya, Kyushu University, Fukuoka, Japan) was cultured statically in tryptic soy broth (Difco) at $37^{\circ} \mathrm{C}$ for $24 \mathrm{~h}$.

Experimental infections. Mice were infected intravenously (i.v.) with $1 \times 10^{6}$ c.f.u. of $L$. monocytogenes. PSK (Kureha Chemical Co., Tokyo, Japan) was dissolved in physiological saline and given intraperitoneally (i.p.) to mice $(0.2 \mathrm{ml})$ in a dose of $5 \mathrm{mg}$ per mouse per injection in a single injection at 10,7 or $4 \mathrm{~d}$ before infection or in daily injections from 10 to $4 \mathrm{~d}$ before the infection. Survival rates were observed for up to $7 \mathrm{~d}$ after the infection.

$O_{\overline{2}}^{-}$production by $M \phi s$. Peritoneal exudate cells (PECs) from mice given i.p. injections of PSK or $10 \%(\mathrm{w} / \mathrm{v})$ peptone $(2 \mathrm{ml})$ were harvested in Hanks' balanced salt solution (HBSS) and suspended $\left(2.5 \times 10^{5} \mathrm{cells}^{-1}\right)$ in Eagle's minimal essential medium (MEM) (Nissui Pharmaceutical Co.) containing $10 \%(\mathrm{v} / \mathrm{v})$ foetal bovine serum (FBS) (M. A. Bioproducts Co.). The resultant cell suspension $(1 \mathrm{ml})$ was poured onto $16 \mathrm{~mm}$ culture wells (Corning), each containing a $14 \mathrm{~mm}$ plastic culture sheet (Wako Pure Chemical), and incubated in a $\mathrm{CO}_{2}$ incubator $\left(5 \% \mathrm{CO}_{2}, 95 \%\right.$ humidified air) at $37^{\circ} \mathrm{C}$ for $2-3 \mathrm{~h}$. The culture sheet was then thoroughly rinsed with PBS to remove nonadherent cells. $\mathrm{M} \phi$ monolayer cultures were then incubated in a $\mathrm{CO}_{2}$ incubator for $30 \mathrm{~min}$, in $10 \%$ (v/v) FBS-MEM containing $0.1 \%(\mathrm{w} / \mathrm{v})$ nitroblue tetrazolium (NBT), with or without the addition of $10 \mathrm{or} 100 \mathrm{ng}$ phorbol myristate acetate (PMA; Sigma) $\mathrm{ml}^{-1}$. The $\mathbf{M} \phi$ monolayer sheet was then fixed with formaldehyde and the percentage of NBT-reducing cells was counted. $\mathrm{O}_{2}^{-}$generated in $\mathrm{M} \phi$ reduces NBT, producing a blue pigment in the cytoplasm (Krueger et al., 1976).

Chemiluminescence of $M \phi s$. PECs induced with PSK or peptone were resuspended $\left(10^{6}\right.$ cells $\left.\mathrm{ml}^{-1}\right)$ in $1 \mathrm{ml}$ phenol-red-free HBSS containing $0.1 \mathrm{~mm}$-luminol. After warming at $37^{\circ} \mathrm{C}$ for $1 \mathrm{~min}$, the background photoemission was counted in a luminometer (Lumicounter ATP-237, Toyo Kagaku Sangyo, Tokyo) for $10 \mathrm{~s}$ and the PMA-triggered chemiluminescence (CL) was measured at intervals for up to $5 \mathrm{~min}$ after the addition of PMA dissolved in $10 \mu \mathrm{l}$ dimethylsulphoxide, to give a final concentration of $100 \mathrm{ng} \mathrm{ml}^{-1}$.

\section{RESULTS}

Alteration in oxidative metabolism of host M oxygen metabolism of host $\mathrm{M} \phi \mathrm{s}$, based on PMA-triggered $\mathrm{O}_{2}^{-}$production and $\mathrm{CL}$. Table 1 shows changes in the $\mathrm{O}_{2}^{-}$production by host peritoneal $\mathrm{M} \phi \mathrm{s}$ in response to PMA after a single injection (i.p.) of PSK. A marked increase in $\mathrm{O}_{2}^{-}$-producing ability of host $\mathrm{M} \phi \mathrm{s}$ was seen around 4-7 d after injection of either 1 or $5 \mathrm{mg}$ of PSK per mouse. The enhanced $\mathrm{O}_{2}^{-}$-generating state persisted for up to $21 \mathrm{~d}$ after the PSK injection and declined thereafter. At $4 \mathrm{~d}$ after the PSK injection, there was an increase in the spontaneous $\mathrm{O}_{2}^{-}$production of host $\mathrm{M} \phi \mathrm{s}$. A marked enhancement of $\mathrm{CL}$ was seen around $4 \mathrm{~d}$ after PSK treatment, a much higher response being observed in $\mathrm{M} \phi \mathrm{s}$ from mice given $5 \mathrm{mg}$ PSK per mouse than those given only $1 \mathrm{mg}$ (Fig. 1). It is possible that the peak of CL appeared earlier than day 4. The enhanced state of $M \phi C L$ rapidly returned to normal thereafter, indicating that, on the basis of CL function of $\mathrm{M} \phi \mathrm{s}$, PSK-induced activation of $\mathrm{M} \phi$ is transient.

To determine whether PSK primes $\mathrm{M} \phi$ s systemically, we studied the effect of PSK given as a single i.v. injection on $\mathrm{O}_{2}^{-}$generation by host peritoneal $\mathrm{M} \phi$ s induced with peptone (Table 2). Although the peptone-induced $\mathrm{M} \phi$ s from control mice showed a considerably more intense $\mathrm{CL}$ than did normal $\mathrm{M} \phi \mathrm{s}$, the preceding PSK injection caused a more marked enhancement of $\mathrm{CL}$ of the peptone-elicited $\mathrm{M} \phi \mathrm{s}$, and this effect was evident around 7-21 d after the PSK priming. In this case, no difference was noted between the priming effect of PSK given in a dose of 1 or $5 \mathrm{mg}$ per mouse. PSK also stimulated or primed host PMNs systemically in respect of their CL response (data not shown).

Effect of PSK given in multiple injections on the M $M$ oxidative burst. Figs 2 and 3 compare the effects of PSK injected i.p. to mice as a single dose or in multiple doses (four and seven injections) on $\mathrm{O}_{2}^{-}$production and the $\mathrm{CL}$ response of host peritoneal $\mathrm{M} \phi \mathrm{s}$. In both cases, no significant difference was noted in the level of $\mathbf{M} \phi$ stimulation whether single, four, or seven injections of the agent were given. Similarly, the $M \phi$-priming activity of PSK was not enhanced by multiple injections (data not shown). 


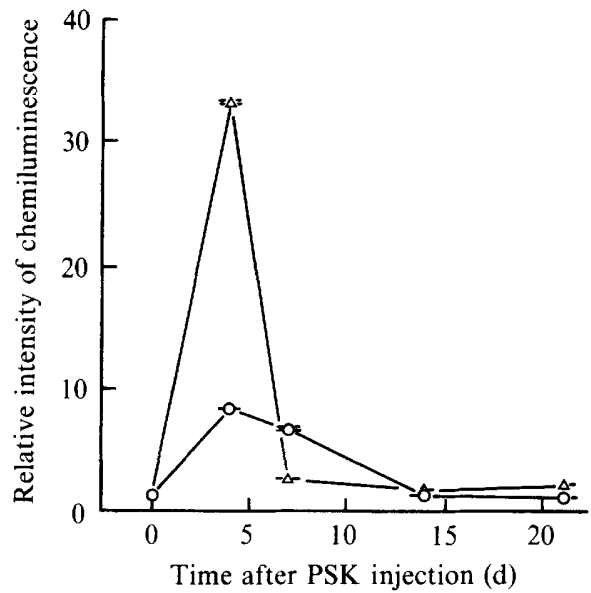

Fig. 1. Effect of PSK on PMA-induced CL of host peritoneal M $\phi$ s. Mice were given PSK i.p. at a dose of $1 \mathrm{mg}(\mathrm{O})$ or $5 \mathrm{mg}(\triangle)$ per mouse and the peritoneal M $\phi$ s were harvested and measured for $\mathrm{CL}$ in response to $100 \mathrm{ng}$ PMA ml-1 at the indicated times. The relative intensity of CL of a given M $\phi$ population was calculated as (cumulative counts from 1 to $5 \mathrm{~min}$ after PMA-triggering of test $\mathrm{M} \phi \mathrm{s}) /($ cumulative counts of resident $\mathrm{M} \phi \mathrm{s}$ ). The resident $\mathrm{M} \phi \mathrm{s}$ gave a $\mathrm{CL}$ reading of $13020 \mathrm{c}$.p.m. per $10^{6}$ cells in response to PMA as a peak value and the value for cumulative counts was 55290 . Each symbol indicates the mean \pm SEM of two incubation mixtures of pooled PECs.

Table 1. Enhancement of $\mathrm{O}_{2}^{-}$-producing ability of peritoneal $M \phi s$ after i.p. injection of PSK

Mice were given PSK i.p. at the indicated dose on day 0 , and the $\mathrm{O}_{2}^{-}$-producing ability of host peritoneal $\mathrm{M} \phi \mathrm{s}$ in the presence or absence of $100 \mathrm{ng} \mathrm{PMA} \mathrm{ml}{ }^{-1}$ was measured on the days indicated after PSK injection.

Time of $\mathbf{M} \phi$ harvest after PSK injection (d)

$$
4
$$

21

28

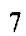

14
PSK

injection (mg per mouse)*

-
1
5
-
1
5

-
5

$$
1
$$$$
5
$$

$-$

$\mathrm{O}_{2}^{-}$production of $\mathrm{M} \phi \mathrm{s}$ $(\%$ of $\mathrm{M} \phi$ s reducing $\mathrm{NBT}) \dagger$

$\overbrace{\text { Spontaneous }}$ PMA-triggered

$$
\begin{aligned}
& 0 \cdot 2 \pm 0 \cdot 2 \\
& 13 \pm 1 \\
& 14 \pm 1 \\
& 1 \cdot 6 \pm 0 \cdot 2 \\
& 1 \cdot 4 \pm 0 \cdot 3 \\
& 1 \cdot 4 \pm 0 \cdot 9 \\
& 0 \cdot 3 \pm 0 \cdot 3 \\
& 0 \cdot 8 \pm 0 \cdot 1 \\
& 7 \cdot 6 \pm 4 \cdot 6 \\
& 0 \cdot 5 \pm 0.5 \\
& 1 \cdot 1 \pm 0 \cdot 1 \\
& 1 \cdot 1 \pm 0.5 \\
& 0 \cdot 8 \pm 0 \cdot 2 \\
& 1 \cdot 1 \pm 0.6 \\
& 0.8 \pm 0.7
\end{aligned}
$$

Increase in PMAtriggered $\mathrm{O}_{2}^{-}$ production after PSK injection $(\%)$

$\begin{array}{lr}32 \pm 1 & \\ 66 \pm 1 & 106 \\ 67 \pm 4 & 109 \\ 22 \pm 2 & \\ 41 \pm 1 & 86 \\ 55 \pm 1 & 150 \\ 37 \pm 2 & \\ 64 \pm 1 & 73 \\ 67 \pm 9 & 81 \\ 40 \pm 12 & \\ 76 \pm 3 & 90 \\ 78 \pm 3 & 95 \\ 48 \pm 2 & \\ 68 \pm 7 & \\ 60 \pm 9 & 42 \\ & \end{array}$

*-, Solute control.

$\dagger$ The results are means \pm SEM of two incubations of pooled $M \phi s$ from four or five mice.

Effect of PSK on host resistance to listerial infection. As indicated above, PSK is thought to enhance the oxygen metabolism of host $\mathbf{M} \phi \mathrm{s}$ in a direct and systemic manner and by so doing to potentiate their antimicrobial activity, especially against intracellular parasites including Listeria monocytogenes (Klebanoff \& Hamon, 1975; Nathan, 1983). We therefore examined the effect of PSK on host resistance to listerial infection. When mice were injected i.p. with PSK $(5 \mathrm{mg}$ ) in a single dose at 10,7 or $4 \mathrm{~d}$ before i.v. injection with $L$. monocytogenes, their survival at 


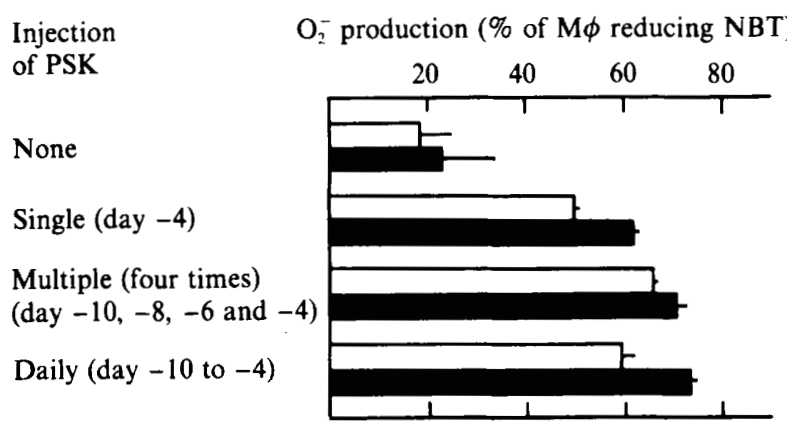

Fig. 2

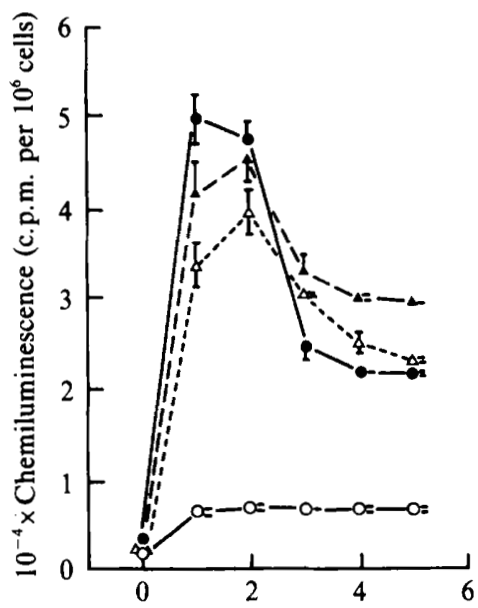

Time after PMA triggering (min)

Fig. 3

Fig. 2. Comparison of single and multiple injections of PSK for efficacy in enhancing $\mathrm{O}_{2}^{-}$production of peritoneal $\mathrm{M} \phi \mathrm{s}$ in response to 10 (open bars) and 100 (shaded bars) $\mathrm{ng}$ PMA ml${ }^{-1}$. PSK (1 mg per injection) was given i.p. to mice in the indicated protocols. Each bar indicates the mean \pm SEM of two incubation mixtures of pooled $\mathbf{M} \phi \mathbf{s}$.

Fig. 3. Comparison of single and multiple injections of PSK for efficacy in enhancing CL of peritoneal $M \phi s$ in response to $100 \mathrm{ng}^{\text {PMA ml}}{ }^{-1}$. PSK (1 mg per mouse per injection) was given i.p. to mice in a single dose $4 \mathrm{~d}$ before $\mathrm{M} \phi$ harvest $(\bullet)$, in four doses at $10,8,6$, and $4 \mathrm{~d}$ before harvest $(\triangle)$, or daily from 10 to $4 \mathrm{~d}$ (seven doses) before harvest $(\boldsymbol{\Lambda})$. O, CL of normal M $\phi$ s. Each symbol indicates the mean \pm SEM of two incubation mixtures of pooled PECs.

\section{Table 2. Priming activity of $P S K$ on $O_{2}^{-}$-producing ability of peritoneal $M \phi s$}

Mice were given PSK i.v. at the indicated dose on day 0 , and peptone-induced peritoneal $M \phi$ s were harvested 4-28 d later (peptone was given i.p. $4 \mathrm{~d}$ before $M \phi$ harvest) and assayed for their $\mathrm{O}_{\overline{2}}$ producing ability in the presence or absence of $100 \mathrm{ng}$ PMA ml-1.

Time of $\mathrm{M} \phi$ harvest after PSK injection (d)

4

14

21

28

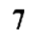

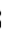

$\mathrm{O}_{2}^{-}$production of $\mathrm{M} \phi \mathrm{s}$ ( $\%$ of $M \phi$ s reducing NBT) $\dagger$

injection (m.g per mouse)*

\begin{tabular}{|c|c|}
\hline $\begin{array}{l}\text { njection } \\
\text { per mouse)* }\end{array}$ & Spontaneou \\
\hline $\begin{array}{l}- \\
1 \\
5\end{array}$ & $\begin{array}{c}5 \cdot 8 \pm 2 \cdot 1 \\
6 \cdot 2 \pm 1 \cdot 3 \\
11+2\end{array}$ \\
\hline $\begin{array}{l}\overline{1} \\
5\end{array}$ & $\begin{array}{l}1.9 \pm 0.4 \\
1.8 \pm 0.2 \\
2.2 \pm 0.6\end{array}$ \\
\hline $\begin{array}{l}- \\
1 \\
5\end{array}$ & $\begin{array}{l}1.0 \pm 0.4 \\
1.9 \pm 0.5 \\
2.8 \pm 0.7\end{array}$ \\
\hline $\begin{array}{l}- \\
1 \\
5\end{array}$ & $\begin{array}{l}2.8 \pm 2.7 \\
5.4 \pm 5.4 \\
2.8 \pm 0.6\end{array}$ \\
\hline $\begin{array}{l}- \\
1 \\
5\end{array}$ & $\begin{array}{l}2 \cdot 1 \pm 0.0 \\
2 \cdot 3 \pm 0 \cdot 3 \\
4 \cdot 1 \pm 4 \cdot 0\end{array}$ \\
\hline
\end{tabular}

Increase in PMAtriggered $\mathrm{O}_{2}^{-}$ production after PSK injection (\%)
PMA-triggered

$$
58 \pm 12
$$$$
70 \pm 3
$$$$
69 \pm 2
$$$$
50 \pm 4
$$$$
74 \pm 4
$$$$
76 \pm 12
$$$$
46 \pm 2
$$$$
61 \pm 2
$$$$
66 \pm 6
$$$$
45 \pm 0
$$$$
68 \pm 3
$$$$
62 \pm 13
$$$$
41 \pm 4
$$$$
49 \pm 1
$$$$
48 \pm 2
$$

*-, Solute control.

$\dagger$ The results are means \pm SEM of two incubations of pooled $M \phi s$. 
3.5 and $7 \mathrm{~d}$ was increased from $0 \%$ (control mice) to $50 \%$ and $20-30 \%$, respectively. A similar increase in the host resistance was noted regardless of the timing of the injection. A similar efficacy was also noted when PSK was given to mice in multiple injections from 10 to $4 \mathrm{~d}$ before the infection. In such cases, it may be noteworthy that the protective effect of PSK is systemic because the agent injected i.p. increased the host resistance against $L$. monocytogenes injected i.v.

\section{DISCUSSION}

As indicated in Tables 1 and 2, the oxidative burst of host $M \phi$ s in response to PMA was enhanced following PSK injection, especially when PSK was administered 4-7 d before M $\phi$ harvest. This indicates the functional activation of M $\phi$ s by PSK, because 'activated' $M \phi s$ possess higher responsiveness to PMA-triggering, in terms of respiratory burst, than do normal M $\phi$ s (Johnston et al., 1978; Nathan \& Root, 1977; Tomioka \& Saito, 1980). About a twofold increase in the number of $M \phi s$ in the peritoneal cavity of host mice was observed from 4 to $14 \mathrm{~d}$ after the injection (i.p.) of PSK, while the number of PMNs was increased only within $4 \mathrm{~d}$ of the PSK injection. Therefore, the $\mathbf{M} \phi$ populations newly accumulated in the peritoneal cavity of host mice after PSK injection may be closely related to the functionally activated state of the host peritoneal $\mathbf{M} \phi \mathbf{s}$.

We noted a marked difference between the patterns of PMA-triggered $\mathrm{O}_{2}^{-}$production and CL response of $M \phi s$, after a single injection (i.p.) of PSK (Table 1 and Fig. 1). An elevated state of $\mathrm{O}_{2}^{-}$-generating ability of host $\mathrm{M} \phi \mathrm{s}$ due to PSK injection persisted, even for up to $28 \mathrm{~d}$ after the injection, whereas the PSK-induced enhancement of $M \phi C L$ was seen only around 4-7 d after the injection. Similar discrepancies were noted between the $\mathrm{H}_{2} \mathrm{O}_{2}$-releasing ability and $\mathrm{CL}$ response of host $\mathbf{M} \phi \mathbf{s}$ during the course of Mycobacterium intracellulare and Listeria monocytogenes infections (Saito et al., 1986a) and between the $\mathrm{O}_{2}^{-}$-producing ability and $\mathrm{CL}$ of host $\mathbf{M} \phi$ s after Lactobacillus casei injection (Saito et al., 1987). M $\phi$ CL has been reported to originate from ${ }^{1} \mathrm{O}_{2}$ and ${ }^{\circ} \mathrm{OH}$ (Sagone et al., 1977) rather than $\mathrm{O}_{2}^{-}$and $\dot{\mathrm{H}}_{2} \mathrm{O}_{2}$. In $\mathrm{M} \phi \mathrm{s},{ }^{1} \mathrm{O}_{2}$ and OH are generated mainly through the Haber-Weiss reaction, catalysed by iron and tryptophan (Halliwell, 1978) and through the peroxidase $/ \mathrm{H}_{2} \mathrm{O}_{2}$-mediated halogenation reaction (Rosen \& Klebanoff, 1977), and these reactions are thought to be regulated by different cellular mechanisms from that related to regulation of PMA-triggering of NADP.H oxidase (Johnston \& Kitagawa, 1985), which generates $\mathrm{O}_{2}^{-}$(Tsunawaki \& Nathan, 1984). Therefore, in the later period after PSK injection, the peritoneal $M \phi s$ are probably still enhanced in the NADPH oxidase system and in the signal transfer system from the PMA-receptor to the enzyme (Johnston \& Kitagawa, 1985) but the ${ }^{1} \mathrm{O}_{2}$ and ${ }^{\circ} \mathrm{OH}$ generating functions are reduced to a normal level. However, the profile of PMA-triggered $\mathrm{O}_{2}^{-}$production differs too much from that of PMA-triggered $\mathrm{CL}$ to be fully explained by the above reasoning. Because $\mathrm{HOCl}$, which is generated in a $\mathrm{H}_{2} \mathrm{O}_{2}$-mediated halogenation reaction catalysed by peroxidases such as myeloperoxidase and lactoperoxidase or by $\mathrm{Fe}^{2+}$ bound to certain chelating substances (Harrison \& Schultz, 1976), oxidizes luminol resulting in intense photoemission (Seitz, 1975), the PMA-triggered M $\phi C L$ might partly reflect the activity of the halogenation system in a given $\mathrm{M} \phi$ cell. If so, the observed discrepancy between PMA-triggered $\mathrm{O}_{2}^{-}$production and CL may be given an additional explanation, based on the situation that the duration of the elevated state in the halogenation system differs from that in the NADPH oxidase system. The $\mathrm{O}_{2}^{-}\left(\right.$and $\left.\mathrm{H}_{2} \mathrm{O}_{2}\right)-$ producing ability and CL, in response to PMA and other stimuli (Pick \& Keisari, 1981), serve as parameters representing the activated state of $\mathbf{M} \phi \mathbf{s}$ (Johnston et al., 1978; Karnovsky \& Lazdins, 1978; Nathan \& Root, 1977; Schleupner \& Glasgow, 1978). Oúr present observations indicate that the two parameters are not always in concert, particularly with respect to the timing of their alteration patterns after $\mathbf{M} \phi$ stimulation. It remains to be determined which parameter more adequately represents the 'activated state of $\mathbf{M} \phi \mathbf{s}$ ', including differentiation of the 'immunologically activated state' (Karnovsky \& Lazdins, 1978) from the merely 'stimulated state' (Karnovsky \& Lazdins, 1978; Tomioka \& Saito, 1980). 
We also found that PSK to some extent enhanced the host resistance to Listeria monocytogenes infection in mice. Regardless of the timing of PSK injection(s) in a period of $10-4 \mathrm{~d}$ before the infection, the agent enhanced the host resistance to $L$. monocytogenes in a similar fashion. This suggests the importance of the priming action of the agent on $\mathbf{M} \phi$ functions, as revealed in experiments shown in Table 2, or by an action which accelerates emigration of blood monocytes to the site of infection (North, 1970). We observed that Lactobacillus casei, a bacterial immunopotentiator (Kato et al., 1981), stimulated not only the cellular functions of fixed $\mathbf{M} \phi \mathrm{s}$ in the reticuloendothelial system but also the accumulation of free $\mathrm{M} \phi \mathrm{s}$ (blood monocytes) at the site of listerial infection. The latter is important for expression of the protective activity of Lactobacillus casei against Listeria monocytogenes infection (Sato, 1984).

Multiple injections of PSK did not increase the protective efficacy of the agent as compared to a single injection. This may be explained by the finding that both the $\mathrm{O}_{2}^{-}$-producing ability and the CL of host $M \phi$ s were similarly enhanced by either multiple PSK injections or a single injection (Figs 2 and 3). Although the reason for this phenomenon is unknown, it suggests that multiple injections of PSK would probably be of little benefit in controlling infection in a clinical situation. It may be noteworthy that some immunopotentiators, such as OK-432 (streptococcal preparation) and LC 9018 (Lactobacillus casei preparation), induced potent suppressor $\mathrm{M} \phi \mathrm{s}$ in the spleen of host animals when administered in multiple injections (Tomioka \& Saito, 1985; unpublished results). In preliminary experiments, we also found that PSK given in a large dose elicited suppressor cells among mouse splenocytes (unpublished observations).

Our study has shown that PSK enhances the resistance of mice to infection by Listeria monocytogenes. Since PSK has few side effects (Tsukagoshi et al., 1984), it may be useful for immunotherapy of immunocompromised hosts.

We thank Kureha Chemical Co., Tokyo, for providing PSK.

\section{REFERENCES}

Borsos, T. \& RAPP, H. J. (editors) (1973). Conference on the use of BCG in therapy of cancer. National Cancer Institute Monograph no. 39.

Halliwell, B. (1978). Superoxide-dependent formation of hydroxyl radicals in the presence of iron chelates. FEBS Letters 92, 321-326.

Halpern, B., Fray, A., Crepin, Y., Platic, O., Lorient, A. M., Rabourdin, A., Sparros, L. \& IsAC, R. (1973). Corynebacterium parvum, a potent immunostimulant in experimental infections and in malignancies. In Immunopotentiation, Ciba Foundation Symposium 18 (new series), pp. 217-236. Edited by P. Medawar. Amsterdam: Elsevier Excerpta Medica North-Holland.

Harrison, J. E. \& Schultz, J. (1976). Studies on the chlorinating activity of myloperoxidase. Journal of Biological Chemistry 251, 1131-1374.

JoHNSTON, R. B., JR (1978). Oxygen metabolism and microbicidal activity of macrophages. Federation Proceedings 37, 2759-2764.

Johnston, R. B., JR \& KitaGaWA, S. (1985). Molecular basis for the enhanced respiratory burst of activated macrophages. Federation Proceedings 44, 2927 2932.

Johnston, R. B., JR, Godzik, C. A. \& Cohn, Z. A. (1978). Increased superoxide anion production by immunologically activated and chemically elicited macrophages. Journal of Experimental Medicine 148, 115-127.

KaRnovsky, M. L. \& LAzdins, K. (1978). Biochemical criteria for activated macrophages. Journal of $\mathrm{Im}$ munology 121, 809-813.
Kato, I., Kobayashi, S., Yokokura, T. \& MutaI, M. (1981). Antitumor activity of Lactobacillus casei in mice. Gann 72, 517-523.

KlebanofF, S. J. \& Hamon, C. B. (1975). Antimicrobial system of mononuclear phagocytes. In Mononuclear Phagocytes in Immunity, Infection and Pathology, pp. 507-531. Edited by R. van Furth. Oxford: Blackwell Scientific Publications.

Krueger, G. G., Ogden, B. E. \& Weston, W. L. (1976). In vitro quantitation of cell-mediated immunity in guinea-pigs by macrophage reduction of nitroblue tetrazolium. Clinical and Experimental Immuno$\log y 23,517-524$.

MAYER, P. \& DREWS, J. (1980). The effect of a proteinbound polysaccharide from Coriolus versicolor on immunological parameters and experimental infections in mice. Infection and Immunity 8, 13-21.

Nathan, C. F. (1983). Mechanisms of macrophage antimicrobial activity. Transactions of the Royal Society for Tropical Medicine and Hygiene 77, 620-630.

Nathan, C. F. \& Root, R. K. (1977). Hydrogen peroxide release from mouse peritoneal macrophages. Dependence on sequential activation and triggering. Journal of Experimental Medicine 146, 1648-1662.

Nathan, C. F., Nogeira, N., Juangbhanichi, C., Ellis, J. \& CoHN, Z. A. (1979). Activation of macrophages in vivo and in vitro. Correlation between hydrogen peroxide release and killing of Trypanosoma cruzi. Journal of Experimental Medicine 149, 1056-1068. 
Nguyen, B. T. \& Stadtsbaeder, S. (1980). Comparative biological and antitoxoplasmic effects of particulate and water soluble polysaccharides, in vitro. In Macrophages and Lymphocytes, Nature, Functions, and Interaction, Part A, pp. 255-268. Edited by M. R. Escobar \& H. Friedman. New York: Plenum Press.

Nомото, K. (1981). The mechanism of immunomodulation by polysaccharides of lipopolysaccharides. Japanese Journal of Clinical Medicine 39, 1868-1873.

NoRTH, R. J. (1970). The relative importance of blood monocytes and fixed macrophages to the expression on cell-mediated immunity to infection. Journal of Experimental Medicine 132, 521-534.

PICK, E. \& KeISARI, Y. (1981). Superoxide anion and hydrogen peroxide production by chemically elicited peritoneal macrophages - induction by multiple nonphagocytic stimuli. Cellular Immunology 59, 301-318.

Rosen, H. \& KLEBanoff, S. J. (1977). Formation of singlet oxygen by myeloperoxidase mediated antimicrobial system. Journal of Biological Chemistry 252, 4803-4810.

Sagone, A. L., JR, Mendelson, D. S. \& Metz, E. N. (1977). The effect of sodium azide on the chemiluminescence of granulocytes. Evidence for the generation of multiple oxygen radicals. Journal of Laboratory and Clinical Immunology 89, 1333-1341.

Saito, H., Tomioka, H., Yamada, Y. \& JidoI, J. $(1986 a)$. Oxidative and phagocytic functions of macrophages during infections induced in mice by Mycobacterium intracellulare and Listeria monocytogenes. Journal of General Microbiology 132, $1117-1125$.

Saito, H., Watanabe, T. \& Horikawa, Y. (1986 b). Effects of Lactobacillus casei on Pseudomonas aeruginosa infection in normal and dexamethasonetreated mice. Microbiology and Immunology 30, 249-259.

Saito, H., Tomioka, H. \& Nagashima, K. (1987). Protective and therapeutic efficacy of Lactobacillus casei against experimental murine infections due to
Mycobacterium fortuitum complex. Journal of General Microbiology 133, 2843-2851.

SATO, K. (1984). Enhancement of host resistance against Listeria infection by Lactobacillus casei: role of macrophages. Infection and Immunity 44, 445451.

Schleupner, C. J. \& Glasgow, L. A. (1978). Peritoneal macrophage activation indicated by enhanced chemiluminescence. Infection and Immunity 21, 886-895.

SeITZ, W. R. (1975). Chemiluminescence from reaction between hypochlorite and luminol. Journal of Physical Chemistry 79, 101-106.

Shiraishi, A., Mikami, Y. \& Arai, T. (1979). Protective effect of $\mathrm{OK}-432$ (a streptococcal preparation) on experimental candidasis. Microbiology and Immunology 23, 549-554.

TomioKa, H. \& SAITo, H. (1980). Hydrogen peroxidereleasing function of chemically elicited and immunologically activated macrophages: differential response to wheat germ lectin and concanavalin $\mathbf{A}$. Infection and Immunity 29, 469-476.

TomioKa, H. \& SAITo, H. (1985). Dual effects of OK432 on mitogenic response of splenocytes to concanavalin A. Microbiology and Immunology 29, 349-358.

Tsukagoshi, S., Hashimoto, Y., FujI, G., Kobayashi, H. Nomoto, K. \& Orita, K. (1984). Krestin (PSK). Cancer Treatment Review 11, 131-155.

Tsunawaki, S. \& Nathan, C. F. (1984). Enzymatic basis of macrophage activation. Kinetic analysis of superoxide production in lysates of resident and activated mouse peritoneal macrophage and granulocytes. Journal of Biological Chemistry 259, 4305-4312.

Uetsuxa, A., Satoh, S. \& Ohno, Y. (1980). Protective effect of PSK, a protein-bound polysaccharide preparation, against candidiasis in tumor-bearing mice. In Macrophages and Lymphocytes, Nature, Functions, and Interaction, Part B, pp. 21-31. Edited by M. R. Escobar \& H. Friedman. New York: Plenum Press. 